\title{
End-stage cystic fibrosis lung disease is characterised by a diverse inflammatory pattern: an immunohistochemical analysis
}

\author{
Elise J. Lammertyn ${ }^{1 *}$, Elly Vandermeulen ${ }^{1}$, Hannelore Bellon', Stephanie Everaerts', Stijn E. Verleden', \\ Kathleen Van Den Eynde², Ken R. Bracke, Guy G. Brusselle, Pieter C. Goeminne', Erik K. Verbeken², \\ Bart M. Vanaudenaerde ${ }^{1}$ and Lieven J. Dupont ${ }^{4}$
}

\begin{abstract}
Background: Cystic fibrosis (CF) lung disease is characterised by vigorous airway inflammation eventually resulting in severe lung damage. This study aimed to describe the diversity of the inflammatory pattern in end-stage CF lungs by evaluating and quantifying which components of the innate and adaptive immunity are involved, and by assessing whether this is gender-specific.

Methods: CF explant lung tissue $(n=20)$ collected at time of transplantation and control tissue $(n=22)$ was sectioned $(9 \mu \mathrm{m})$ and stained for neutrophils, eosinophils, mast cells, dendritic cells, macrophages, CD4 T cells, cytotoxic T cells and B cells. Quantification with special attention for immune cell location was performed.

Results: Neutrophils, mast cells, dendritic cells, macrophages, CD4 T and cytotoxic T cells were significantly increased in CF compared to controls and there was a disproportionate increase of neutrophils around the airways in CF. Large amounts of lymphoid follicles were found in the CF lung and they had a skewed B cell/T cell composition. Upon subdividing the CF patients into a male and female population, eosinophils, mast cells and CD4 T cells were increased specifically in CF females. In this subpopulation, lymphoid follicles had less B cells and more CD8 T cells.

Conclusion: These data demonstrate a diverse inflammatory response in the CF lung, reflected by an increase of both myeloid and lymphoid immune cells. Inflammation in the CF lung appeared to be gender-specific in our population, as the significant increase of eosinophils, mast cells and CD4 T cells was especially notable in the female subpopulation.
\end{abstract}

Keywords: Cellular immune system, Histopathology, Lung immunopathology

\section{Background}

Cystic fibrosis $(\mathrm{CF})$ is the most prevalent autosomal recessive disorder in the Caucasian population and is caused by mutations in the cystic fibrosis transmembrane conductance regulator (CFTR) gene $[1,2]$. Loss of CFTR-mediated chloride and bicarbonate transport leads to dehydration of the airway surface fluid layer and impaired mucociliary clearance. As a result, desiccated

\footnotetext{
* Correspondence: Elise.lammertyn@kuleuven.be

${ }^{1}$ Laboratory of Respiratory Diseases, Department of Clinical and Experimental Medicine, University of Leuven, UZ Herestraat 49, Box 7063000 Leuven, Belgium

Full list of author information is available at the end of the article
}

secretions obstruct the airways and prevent bacterial elimination, establishing chronic infection, commonly with Pseudomonas aeruginosa, and leading to bronchiectasis $[3,4]$. These events are followed by vigorous airway inflammation and may eventually result in severe lung damage, the principal cause of death or reason for transplantation in these patients [4-6].

Neutrophil-dominated airway inflammation of the CF lung environment is a well-established concept: bacterial pathogens interact with epithelial cells and alveolar macrophages, which are part of the lung's innate cellular surveillance system, causing them to release proinflammatory mediators leading to excessive recruitment 
of neutrophils into the bronchoalveolar compartments of the lung $[7,8]$. When chronic infection is established, dendritic cells and $\mathrm{T}$ cells also become activated, the latter releasing even more cytokines contributing to the excessive and perpetual recruitment of neutrophils. This immune response is unable to resolve the infection and massive amounts of oxidants and proteases are released $[7,8]$. The inflammatory cellular pattern of CF lung disease is presumably diverse, given the many different mediators present, but remains insufficiently studied. Besides the key players listed above, data on other immune cells within the CF lung such as eosinophils, mast cells, cytotoxic T cells and B cells, are scarce [9-12]. A diverse inflammatory pattern in CF may also be anticipated based on the genotypic variation and the broad range of bacteria and fungi attacking the lungs, which may result in a pathogen-specific CD4 T cell response [7].

Another phenomenon indicative of the diversity of CF lung disease is the CF 'gender gap'. There seems to be a discrepancy between the median survival of male and female CF patients. This CF 'gender gap' was first described in the 1990's [13]. A large retrospective cohort analysis of the US CF registry, comprising over 20000 patients between 1988 and 1992, showed that females had a $60 \%$ greater chance of dying compared to males, and this effect remained significant even after adjusting for lung function, pancreatic insufficiency and age at diagnosis [14]. Harness-Brumley et al. demonstrated that in 2014, CF females still have a decreased median life expectancy (36.0 years versus 38.7 years in males) and that female gender is a risk factor for death [15]. Morbidity is also increased in female CF patients, with a significantly higher use of intravenous (I.V.) antibiotics, macrolides and steroids, and an increased number of days spent in the hospital [16].

In this study, we aimed to describe the diversity of the inflammatory pattern in the CF lung by quantifying and localising the different immune cells within end-stage CF lungs. Furthermore, we wanted to investigate whether there is a different inflammatory signature in male versus female CF patients.

\section{Methods}

\section{Study material}

CF explant lung tissue was collected at the moment of lung transplantation (LTx) (procedures performed between 2000 and 2012). Control lung tissue was obtained from two different patient populations: firstly, patients who had no underlying lung disease and had a nonrespiratory cause of death (abscess aorta, rectal adenocarcinoma, chronic kidney insufficiency, acute liver failure, sepsis, pancreatitis, ALS, hemoperitoneum) and underwent autopsy, and secondly, patients with a non-metastasized lung tumour. In this case, tissue was taken as far away from the tumour as possible. For the former group, lung function tests were not available, and for the latter, patients were only included if they had a lung function within normal limits. The use of lung tissue for scientific research was approved by the local ethics committee (S52174) and the biobankboard (S51577).

Patient data were collected via the electronic patient files or via the referring centre. Details on the collected data are mentioned in Additional file 1.

\section{Immunohistochemistry}

Nine $\mu \mathrm{m}$ thick sections (mean surface area: $322 \mathrm{~mm}^{2}$ ) were prepared from formalin-fixed paraffin-embedded tissue from each of the subjects and stained for CD4 T cells, cytotoxic T cells (CD8), dendritic cells (CD1a and CD207), eosinophils (EG-2), mast cells (tryptase), neutrophils (MPO) and macrophages (CD163). Additional details and an overview of all used primary and secondary antibodies together with the appropriate chromogen are provided in Additional file 1.

\section{Image analysis}

Images of tissue sections were recorded with a BX61 light microscope (Olympus, Aartselaar, Belgium). All myeloid cells (dendritic cells, neutrophils, macrophages and mast cells) were counted in 10 randomly selected high-power fields (HPF) per three compartments (airway, parenchyma and perivascular). Parenchyma was defined as the absence of airways and blood vessels. Cell countings in the perivascular compartment did not include cells lying inside the lumen of the vessel. In the case of a HPF including both an airway and an accompanying blood vessel, only the cells in the immediate proximity of the airway were counted. All cell types were captured with a 200× magnification. Cell type counts were expressed as cells per HPF for the three compartments separately and also in total, which was an average of the counts in the different compartments. Staining reliability and quality was verified by an experienced pathologist (EKV) before analysis. To assess counting reliability, inter-and intra-observer variability was calculated by means of a Spearman's rank correlation coefficient. Myeloid cell counts were repeated by the first author (EJL) and the second author (EV) in eight subjects (four randomly chosen controls and four CF patients) (Additional file 1: Table S2).

For lymphoid B (CD20) and T (CD4, CD8) cells, quantification was different as it was performed by counting all scattered cells and follicles (i.e. cells aggregated as lymphoid tissue) visible on the section and normalizing the result over the total area of the section. This resulted in the number of scattered cells and follicles being expressed as cells or follicles per $\mathrm{mm}^{2}$ area unit. This method was used because of the inhomogeneous spread 
of lymphoid cells (i.e. presence of follicles). As such, classification of the scattered cells under one of the three compartments was not possible. Next, the percentage of positive $\mathrm{B}$ and $\mathrm{T}$ cells within the follicle was estimated. For each staining (CD20-CD4-CD8), we allocated a percentage (in steps of 10\%) of positivity to each individual follicle (therefore, each follicle was included in the analysis) which we used to study differences in composition. Also, the size and localization of the follicles (airways, parenchyma, and perivascular) was noted. More details on follicle analysis and exact numbers of follicles counted are provided in Additional file 1.

\section{Statistical analysis}

GraphPad Prism 4.0 Software (San Diego, CA, USA) was used for univariate statistical analysis. Results are expressed in numbers (percentage), as mean \pm SEM or as median (IQR). When appropriate, differences in categorical variables were determined using a chi square test. Differences in continuous variables between two groups (control subjects and CF patients) were tested using a Mann-Whitney $U$ test, and for comparison between three groups (compartments and control subjects vs. male $\mathrm{CF}$ patients vs. female CF patients), a Kruskal-Wallis 1-way analysis of variance (ANOVA) in combination with a Dunn's post hoc test was used. A $p$-value $<0.05$ was considered significant. Intra-observer and inter-observer reliability was evaluated by the calculation of Spearman's rank correlation coefficients.

\section{Results}

\section{Patient characteristics}

CF patients $(n=20)$ were significantly younger than control patients $(n=22)(p<0.0001)$. There was no significant difference in gender $(p=0.77)$. There were no significant differences in patient characteristics between male and female CF patients, although a trend towards significantly lower age and higher $\mathrm{FEV}_{1}$ was seen in females (Table 1).

\section{Myeloid cell quantification and localization in end-stage CF lung tissue}

Neutrophil counts were significantly increased in CF tissue compared with controls $(p=0.0024)$, which was due to an increased presence of neutrophils around the CF airways $(p<0.0001)$ (Table 2 and Fig. 1$)$. In CF patients, neutrophils were disproportionally more prevalent around the airways as they were found more than twice as much in this compartment compared with parenchyma $(p<0.01)$ or perivascular $(p<0.001)$ (Additional file 1: Table S4).

There was no difference in the number of eosinophils between control and $\mathrm{CF}$ tissue, regardless whether we considered the whole sample or analysed per compartment (Table 2, Fig. 1).
Table 1 Demographic characteristics of control subjects and CF patients, with a distinction between males and females

Characteristics of control subjects and CF patients

$$
\text { Control subjects CF patients p-value }
$$

Number of patients $(n) \quad 22$

$\begin{array}{llll}\text { Female gender }(n) & 10(45 \%) & 10(50 \%) & 0.77 \\ \text { Mean age }( \pm \text { SEM) (years) } & 61.0( \pm 2.7) & 29.5( \pm 3.5) & <0.0001^{* * *}\end{array}$

Characteristics of male and female CF patients

$\begin{array}{llll} & \text { Male } & \text { Female } & p \text {-value } \\ \text { Number of patients }(n)(\%) & 10(50 \%) & 10(50 \%) & 1.00 \\ \begin{array}{l}\text { Mean age }( \pm \text { SEM) (years) } \\ \text { Mean FEV }\end{array} \text { ( } \pm \text { SEM) } & 31.6( \pm 3.5) & 27.3( \pm 6.1) & 0.052 \\ \text { (\% predicted) } & 25.6( \pm 2.3) & 30.6( \pm 1.5) & 0.052\end{array}$

CFTR genotype (n) (\%)

\begin{tabular}{|c|c|c|c|}
\hline$\Delta F 508 / \Delta F 508$ & $4(40 \%)$ & $6(60 \%)$ & 0.30 \\
\hline$\Delta$ F508/other & $4(40 \%)$ & $4(40 \%)$ & \\
\hline other/other & $2(20 \%)$ & $0(0 \%)$ & \\
\hline sal polyposis (n) (\%) & $4(40 \%)$ & $2(20 \%)$ & 0.33 \\
\hline $\begin{array}{l}\text { h urgency listing prior } \\
\text { LTx (n) (\%) }\end{array}$ & $1(10 \%)$ & $4(40 \%)$ & 0.12 \\
\hline $\begin{array}{l}\text { he on waiting list prior } \\
L T X( \pm S E M) \text { (days) }\end{array}$ & $270.6( \pm 147.2)$ & $139.6( \pm 61.8)$ & 0.25 \\
\hline$P( \pm S E M)(m g / L)$ & $50.5( \pm 31.0)$ & $28.0( \pm 8.4)$ & 0.80 \\
\hline $\begin{array}{l}\text { Erential eosinophil count } \\
\text { total WBC ( } \pm \text { SEM) (\%) }\end{array}$ & $2.2( \pm 0.9)$ & $2.1( \pm 0.8)$ & 0.97 \\
\hline al lgE ( \pm SEM) (kU/L) & $89.2( \pm 38.0)$ & $55.8( \pm 14.3)$ & 0.91 \\
\hline $\begin{array}{l}\text { lonization with } P \text {. } \\
\text { uginosa (n) (\%) }\end{array}$ & $8(80 \%)$ & $6(60 \%)$ & 0.33 \\
\hline $\begin{array}{l}\text { ingi cultured from explant } \\
\text { ng material (n) (\%) }\end{array}$ & $7(70 \%)$ & $6(60 \%)$ & 0.64 \\
\hline $\begin{array}{l}\text { of inhaled } \\
\text { ticosteroids (n) (\%) }\end{array}$ & $7(70 \%)$ & $7(70 \%)$ & 1.00 \\
\hline $\begin{array}{l}\text { of oral corticosteroids } \\
(\%)\end{array}$ & $2(20 \%)$ & $1(10 \%)$ & 0.39 \\
\hline $\begin{array}{l}\text { o last pre-LTx I.V. AB } \\
\text { y }( \pm \text { SEM) (days) }\end{array}$ & $48.5( \pm 19.1)$ & $77.9( \pm 61.0)$ & 0.4 \\
\hline
\end{tabular}

Abbreviations: $F E V_{1}$ Forced Expiratory Volume in $1 \mathrm{~s}, C R P$ C-reactive protein, $W B C$ White blood cells, I.V. Intravenous, $A B$ Antibiotic. Significant differences between CF patients and control subjects are indicated with *, with ${ }^{*}=p<0.05,{ }^{* *}=p<0.01$ and ${ }^{* * *}=p<0.001$ data $<0.05$ are captured in bold

Mast cell counts were significantly increased in CF tissue compared with controls $(p=0.018)$ due to higher numbers of mast cells in the parenchyma $(p=0.0024)$ and perivascular $(p=0.0082)$ (Table 2, Fig. 1). Both in $\mathrm{CF}$ and control patients, mast cells occurred proportionally more around airways compared with parenchyma $(p<0.05$ and $p<0.001$ respectively) or perivascular $(p<0.01$ and $p<0.001$, respectively) (Additional file 1 : Table S4). In the CF tissue, we were able to identify 19 airways showing constrictive bronchiolitis (representative image: Additional file 1: Figure S1). Mast cells were 
Table 2 Quantification of myeloid cell types in controls and CF overall and for the three compartments

\begin{tabular}{|c|c|c|c|}
\hline & Controls & $C F$ & $p$-value \\
\hline Neutrophils (MPO) & $17.4(7.1-30.5)$ & $33.7(25.4-47.8)$ & $0.0024^{* *}$ \\
\hline Airway & $15.1(6.3-28.7)$ & $67.5(43.5-81.9)$ & $<0.0001^{* * *}$ \\
\hline Parenchyma & $19.7(7.1-40.6)$ & $28.9(15.3-36.6)$ & 0.18 \\
\hline Perivascular & $9.7(3.5-19.4)$ & $15.2(9.2-18.9)$ & 0.18 \\
\hline Eosinophils (EG-2) & $1.0(0.4-2.9)$ & $2.3(0.3-5.0)$ & 0.82 \\
\hline Airway & $1.7(0.6-5.5)$ & $2.0(0.5-7.7)$ & 0.10 \\
\hline Parenchyma & $1.1(0.3-2.7)$ & $1.1(0.1-3.6)$ & 0.63 \\
\hline Perivascular & $0.6(0.1-1.7)$ & $0.4(0.0-2.0)$ & 0.61 \\
\hline Mast cell (tryptase) & $10.5(8.8-14.4)$ & $17.6(12.5-24.7)$ & $0.018^{*}$ \\
\hline Airway & $18.8(15.3-31.2)$ & $25.2(19.9-36.6)$ & 0.21 \\
\hline Parenchyma & $7.8(5.0-9.2)$ & $15.0(8.8-21.3)$ & $0.0024^{* *}$ \\
\hline Perivascular & $9.3(6.9-11.1)$ & 12.5 (9.9-15.8) & $0.0082^{* *}$ \\
\hline Dendritic cells (CD1a) & $0.8(0.4-1.5)$ & $3.0(2.1-4.2)$ & $<0.0001 * * *$ \\
\hline Airway & $2.3(0.8-3.6)$ & $4.7(3.0-6.3)$ & $0.0013^{* *}$ \\
\hline Parenchyma & $0.2(0.0-0.5)$ & $2.2(1.0-3.8)$ & $<0.0001^{* * *}$ \\
\hline Perivascular & $0.7(0.1-2.0)$ & $1.6(0.9-3.5)$ & $0.012^{*}$ \\
\hline Dendritic cells (CD207) & $1.0(0.3-1.8)$ & $4.6(3.7-7.6)$ & $<0.0001^{* * *}$ \\
\hline Airway & $3.0(1.6-4.7)$ & $9.6(7.6-13.2)$ & $<0.0001^{* * *}$ \\
\hline Parenchyma & $0.0(0.0-0.2)$ & $2.7(1.1-5.9)$ & $<0.0001^{* * *}$ \\
\hline Perivascular & $0.1(0.0-0.4)$ & $1.2(0.5-4.0)$ & $0.0001^{* * *}$ \\
\hline Macrophages (CD163) & $18.7(10.3-25.1)$ & $32.0(23.0-39.8)$ & $0.0021^{* *}$ \\
\hline Airway & $15.5(8.7-26.6)$ & $33.8(18.4-40.4)$ & $0.0049 * *$ \\
\hline Parenchyma & $21.3(10.6-26.8)$ & $35.0(21.9-46.8)$ & $0.011 *$ \\
\hline Perivascular & $16.9(11.0-21.0)$ & $22.4(14.1-31.6)$ & 0.064 \\
\hline
\end{tabular}

Quantification of the myeloid cell types in control subjects and CF patients overall and for the three compartments (airway, parenchyma and perivascular) separately. The $p$-values in the right-hand column are the result of Mann-Whitney $\mathrm{U}$ testing. Significant differences between CF patients and control subjects are indicated with *, with ${ }^{*}=p<0.05,{ }^{* *}=p<0.01$ and ${ }^{* * *}=p<0.001$

data $<0.05$ are captured in bold

counted and compared to mast cell counts around 19 representative bronchiectatic airways, and there were significantly more mast cells around airways showing constrictive bronchiolitis (48 cells/HPF, IQR 36-57) than around bronchiectatic airways (28 cells/HPF, IQR 15-45) $(p=0.035)$.

CD1a (immature myeloid) dendritic cells were significantly increased in CF tissue compared with controls $(p<0.0001)$. This difference was seen in all compartments (airways: $p=0.0013$, parenchyma: $p<0.0001$ and perivascular: $p=0.012$, versus control) (Table 2, Fig. 1). Likewise, langerin-positive (resident epithelial) dendritic cells (CD207) were significantly increased in CF tissue $(p<0.0001)$ with similar levels of significance for all compartments (airways: $p<0.0001$, parenchyma: $p<0.0001$ and perivascular: $p=0.0001$, versus control)

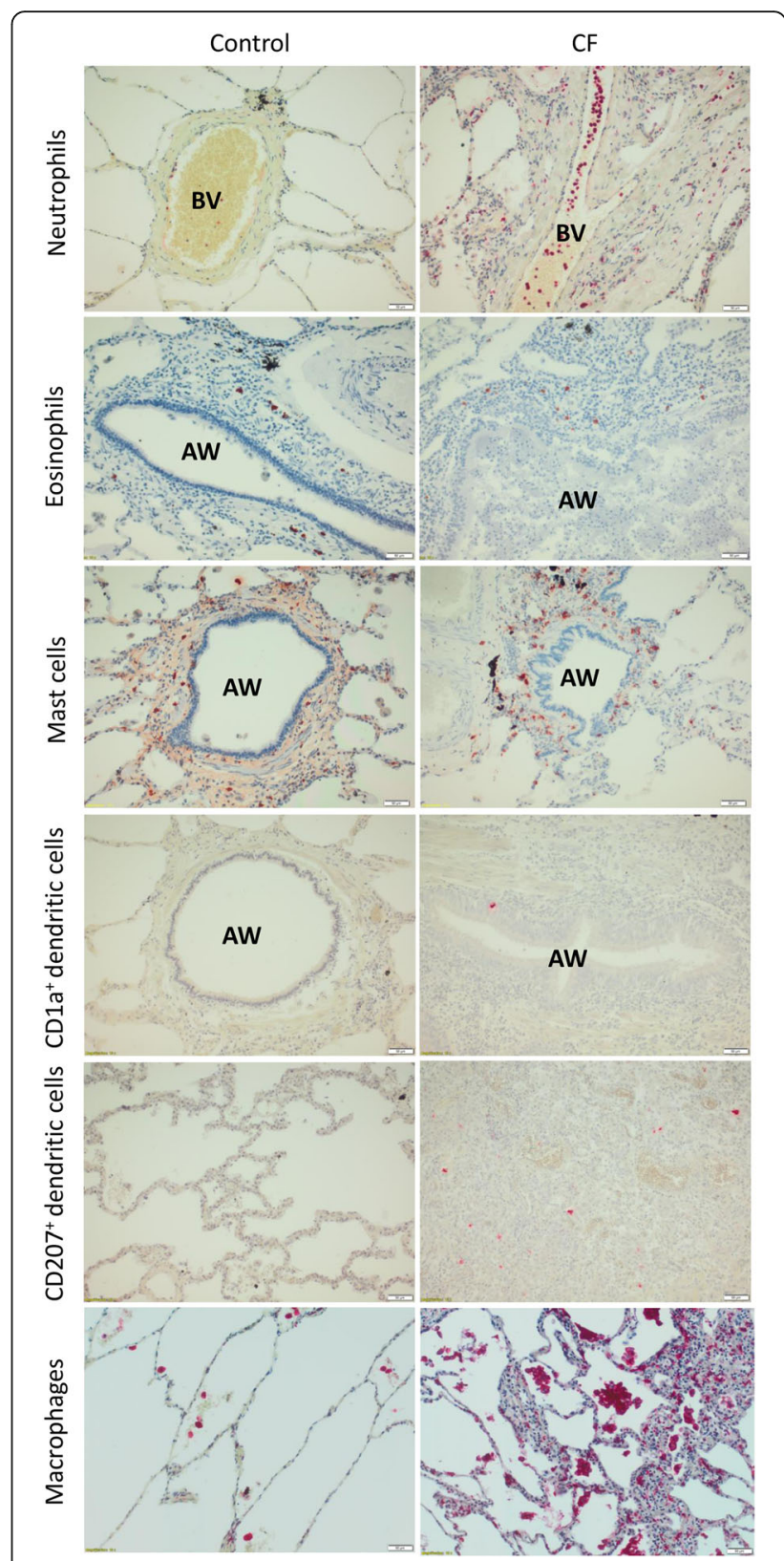

Fig. 1 Histological sections of formalin-fixed paraffin-embedded human lung tissue of control subjects and CF patients. Sections were stained for neutrophils (MPO), eosinophils (EG-2), mast cells (tryptase), dendritic cells (CD1a and CD207) and macrophages (CD163). Scale bar $=50 \mu \mathrm{m}$. Abbreviations: $\mathrm{AW}=$ airway, $\mathrm{BV}=$ blood vessel

(Table 2, Fig. 1). When compared within CF lung tissue, both types of myeloid dendritic cells occurred more around airways compared to parenchyma (CD1a: $p<0.05$, CD207: $p<0.01$ ) or perivascular (CD1a: $p<0.01$, CD207: $p<0.001)$. In control tissue, a similar observation was made for CD207 dendritic cells (airways compared to parenchyma and perivascular: both $p<0.001$ ), while the increased presence of $\mathrm{CD} 1 \mathrm{a}$ dendritic cells around the airways was only significant compared to parenchyma 
$(p<0.001)$, but not to the perivascular compartment (Additional file 1: Table S4).

Macrophage counts were significantly increased in CF tissue compared to controls $(p=0.0021)$ due to increased numbers found around the CF airways $(p=0.0049)$ and in the parenchyma $(p=0.011)$ (Table 2, Fig. 1$)$. Neither CF nor controls showed any differences when compartmental distribution was evaluated (Additional file 1: Table S4).

\section{Lymphoid cell and follicle quantification and localization in end-stage $\mathrm{CF}$ lung tissue}

Both cytotoxic T cell (CD8) and CD4 T cell counts were significantly increased in CF tissue compared to controls ( $p<0.001$ and $p=0.007$, respectively), whereas the slightly increased B cell counts in CF showed only a trend toward significance ( $p=0.091$ versus control) (Table 3, Fig. 2).

Lymphoid follicles (representative image: Additional file 1: Figure S2) were more abundant in CF tissue $(p<0.0001)$, which was observed in all three compartments (airways: $p<0.0001$, parenchyma: $p<0.0001$ and perivascular: $p=0.0002$, versus control) (Table 3, Fig. 2). The size of the follicles did not differ between $\mathrm{CF}$ and control patients (data not shown) but the composition of the follicles did. In lymphoid follicles present in control tissue, CD20 B cells were more abundant than CD4 and CD8 T cells, resulting in a $60 \%-26 \%-14 \%$ distribution respectively. In CF tissue, the proportion of CD4 T cells was significantly increased $(p=0.020$ versus control) giving a $43 \%-39 \%-18 \%$ (CD20, CD4 \& CD8, respectively) distribution (Fig. 3a).

Table 3 Quantification of total lymphoid cell types in controls and CF patients, corrected for area unit

\begin{tabular}{|c|c|c|c|}
\hline \multicolumn{4}{|c|}{$\begin{array}{l}\text { Lymphoid cell and follicle quantification (expressed as cells or follicles/ } \\
\mathrm{mm}^{2} \text { area) }\end{array}$} \\
\hline & Control subjects & CF patients & $\begin{array}{l}\text { Mann-Whitney } \\
U \text { test }\end{array}$ \\
\hline CD4 T cells & $3.8(0.6-7.6)$ & $9.0(2.9-21.7)$ & $0.007^{* *}$ \\
\hline $\begin{array}{l}\text { Cytotoxic } T \\
\text { cells (CD8) }\end{array}$ & $1.5(0.2-11.4)$ & $55.8(23.7-71.5)$ & $<0.0001^{* * *}$ \\
\hline B cells (CD20) & $0.0(0.0-0.9)$ & $0.3(0.1-0.8)$ & 0.091 \\
\hline $\begin{array}{l}\text { Lymphoid } \\
\text { follicles }\end{array}$ & $0.0(0.0-0.009)$ & $0.056(0.022-0.082)$ & $<0.0001^{* * *}$ \\
\hline Airway & $0.0(0.0-0.003)$ & $0.014(0.006-0.029)$ & $<0.0001^{* * *}$ \\
\hline Parenchyma & $0.0(0.0-0.003)$ & $0.011(0.006-0.039)$ & $<0.0001^{* * *}$ \\
\hline Perivascular & $0.0(0.0-0.003)$ & $0.011(0.004-0.023)$ & $0.0002^{* * *}$ \\
\hline
\end{tabular}

During follicle quantification, localization was taken into consideration. The $p$-values in the right-hand column are the result of Mann-Whitney $\mathrm{U}$ testing. Significant differences between CF patients and control subjects are indicated with ${ }^{*}$, with ${ }^{*}=p<0.05,{ }^{* *}=p<0.01$ and ${ }^{* *}=p<0.001$

data $<0.05$ are captured in bold

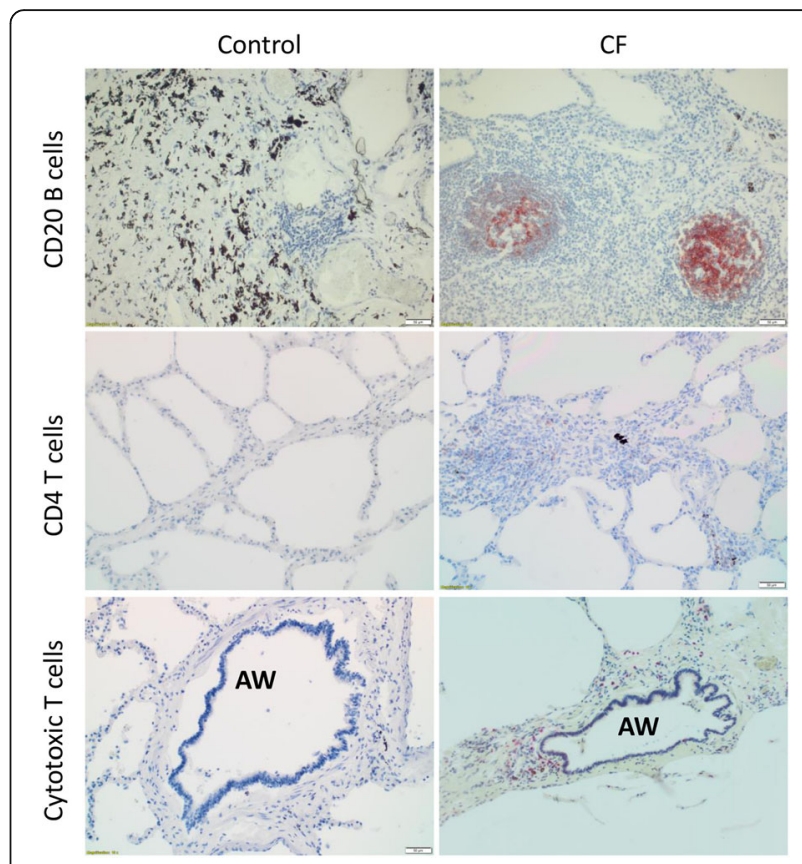

Fig. 2 Histological sections of formalin-fixed paraffin-embedded human lung tissue of control subjects and CF patients. Sections were stained for B cells (CD20), CD4 T cells and cytotoxic T cells (CD8). Scale bar $=50 \mu \mathrm{m}$. Abbreviation: $A W=$ airway

\section{Myeloid and lymphoid cell quantification in the male and female CF subpopulation}

Table 4 shows the results after subdividing the $\mathrm{CF}$ patients in a male and female subpopulation. In control patients there was no significant difference between males and females in the number of myeloid cells, lymphoid cells or follicles present (data not shown).

Concerning the myeloid cells, both eosinophils and mast cells were significantly more abundant in female versus male CF patients (both $p<0.01$ ). As for the lymphoid cells, CD4 $\mathrm{T}$ cell counts were increased in the female CF patients $(p<0.01)$. When comparing each gender to controls, the number of neutrophils, mast cells and CD4 $\mathrm{T}$ cells was significantly higher only in the female CF population $(p<0.05, p<0.001$ and $p<0.001$ respectively). Macrophages on the other hand were only significantly increased in the male CF population $(p<$ $0.01)$. CD20 B cells were equally present in male and female CF patients $(p=0.21)$. Organization in lymphoid tissue (number, size and distribution) was not different between male and female CF patients (Table 4). However, there was a significant difference in lymphoid follicle composition in female CF patients as B cells were less abundant $(p=0.043)$, whereas CD8 T cells were more abundant $(p=0.0029)$ than in male CF patients, resulting in a CD20-CD4-CD8 distribution of 52\%$39 \%-9 \%$ respectively in males, and $34 \%-39 \%-27 \%$ respectively in females (Fig. 3b). 

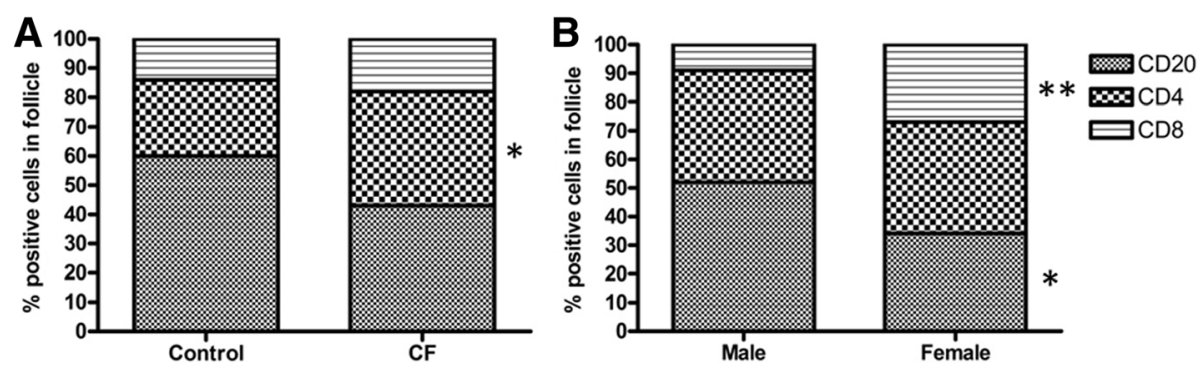

Fig. 3 Composition of the lymphoid follicles found in the lung tissue. Proportions of CD20 B cells, CD4 T cells and CD8 T cells are expressed as percentage positive cells on the total amount of cells in the follicle. Panel (a) shows the difference in distribution of the follicular lymphoid cells between control subjects and CF patients, panel (b) concerns the distribution of the follicular lymphoid cells in CF males and females. Significant differences are indicated with *, with ${ }^{*}=p<0.05$ and ${ }^{* *}=p<0.01$

\section{Correlation with markers of inflammation}

There were no correlations between the myeloid or lymphoid cell counts listed above, and any of the clinical inflammatory parameters (blood eosinophils, CRP, total IgE or IgG) measured in the peripheral blood of the CF patients (last available result before transplant procedure).

\section{Discussion}

The present study demonstrated a significant increase of neutrophils, mast cells, CD1a and CD207 dendritic cells, macrophages, CD8 and CD4 T cells in CF lung tissue. Concomitantly, we found a disproportionate increase of neutrophils around the CF airways. The number of single $\mathrm{B}$ cells was not increased in the $\mathrm{CF}$ lung tissue. The number, but not the size of lymphoid follicles in $\mathrm{CF}$ lungs was increased and there was a skewed B cell/T cell composition. We also found some gender-specific changes in our CF population. Eosinophil, mast cell and
CD4 T cell counts were specifically increased in lung tissue of female CF patients. Lastly, lymphoid follicles had less $\mathrm{B}$ cells and more CD8 T cells in females.

In this study, we have shown that the inflammatory signal in end stage CF lung disease is diverse and involves an increased abundance of both myeloid and lymphoid cells. As more and more players involved in CF lung inflammation are being identified, it becomes increasingly clear how diverse and disturbed the inflammatory pattern really is. This may be the consequence of the presence of mutated CFTR channels on various inflammatory cells. The absence of functional CFTR leads to impaired bacterial killing in murine and human macrophages and a deregulated release of pro-inflammatory cytokines by macrophages during the innate immune response [7]. As the CF lung is liable to infection by a myriad of pathogens, this may also promote the diversity of the immune response. By demonstrating an increase in $\mathrm{T}$ cells and lymphoid follicles in $\mathrm{CF}$, we have

Table 4 Quantification of myeloid and lymphoid cells in controls and CF, with male and female subdivision

\begin{tabular}{|c|c|c|c|c|}
\hline \multicolumn{5}{|c|}{ Myeloid and lymphoid cell type quantification in the male and female CF patient subpopulation compared to control subjects } \\
\hline & Control subjects & Male CF patients & Female CF patients & ANOVA \\
\hline Neutrophils (MPO) & $17.4(7.1-30.5)$ & $30.1(25.4-45.5)$ & $36.3(24.0-51.8)^{*}$ & 0.0009 \\
\hline Eosinophils (EG-2) & $1.0(0.4-2.9)$ & $0.3(0.1-2.3)$ & $4.7(1.8-9.6)^{\S \S}$ & 0.004 \\
\hline Mast cells (tryptase) & $10.5(8.8-14.4)$ & $12.5(7.9-16.5)$ & $23.0(18.7-32.3)^{* * * . \S \S}$ & 0.0005 \\
\hline Dendritic cells (CD1a) & $0.8(0.4-1.5)$ & $2.2(1.5-3.9)^{*}$ & $3.6(2.7-6.6)^{* * *}$ & $<0.0001$ \\
\hline Dendritic cells (CD207) & $1.0(0.3-1.8)$ & $4.3(3.3-8.0)^{* * *}$ & $5.2(2.8-14.3)^{* * *}$ & $<0.0001$ \\
\hline Macrophages (CD163) & $18.7(10.3-25.1)$ & $33.5(23.2-43.2)^{* *}$ & $26.9(16.7-40.5)$ & 0.0058 \\
\hline CD4 T cells & $3.8(0.6-7.6)$ & $2.9(1.2-7.1)$ & $21.7(10.8-29.8)^{* * *, \S \S}$ & $<0.0001$ \\
\hline Cytotoxic T cells (CD8) & $1.5(0.2-11.4)$ & $23.7(12.7-58.6)^{*}$ & $71.5(48.1-115.0)^{* * *}$ & $<0.0001$ \\
\hline B cells (CD20) & $0.0(0.0-0.9)$ & $0.5(0.0-1.3)$ & $0.3(0.1-0.6)$ & 0.21 \\
\hline Lymphoid follicles & $0.0(0.0-0.009)$ & $0.04(0.01-0.1)^{* * *}$ & $0.065(0.028-0.071)^{* * *}$ & $<0.0001$ \\
\hline
\end{tabular}

Quantification of total myeloid and lymphoid cell counts in control subjects and CF patients, with in the latter group a subdivision in the male and female subpopulation. Myeloid cell types are expressed as cells/HPF, whereas the lymphoid cell types or follicles are expressed as cells or follicles/mm ${ }^{2}$ area. The $p$-values in the right-hand column are the result of Kruskal-Wallis 1-way ANOVA testing. Significant differences with control subjects are indicated with *, and significant differences with male CF patients are indicated with ${ }^{\S}$, with ${ }^{*}=p<0.05,{ }^{* *}=p<0.01$ and ${ }^{* * *}=p<0.001$. These values are the results of Dunn's post hoc testing data $<0.05$ are captured in bold 
confirmed the involvement of the cellular adaptive immune response in CF lung disease. A role for $\mathrm{T}$ cells in the pathophysiology of CF has already been suggested as CFTR present on circulating $T$ cells participates in immune cell signalling. This CFTR-mediated signalling is disturbed in CF [7].

A striking finding was the large amount of lymphoid follicles found in all compartments of the CF lung. The presence of follicles is well-established in other chronic inflammatory diseases such as COPD [17]. B cell follicles are the result of lymphoid neogenesis leading to the development of tertiary lymphoid organs in tissues that are under a chronic and constant influence of certain triggers [17]. In end-stage CF, it seems logic that this trigger has an infectious nature as the lungs have endured years of microbial assaults and colonization with different pathogens. Due to the nature of this disease, these pathogens become very difficult to eradicate which results in a sustained immune response with infiltration into the lung parenchyma of macrophages, dendritic cells, $\mathrm{T}$ cells and $\mathrm{B}$ cells. These cells frequently organize themselves at an anatomical and functional level into tertiary lymphoid organs [17]. However, as CF is characterized by airway destruction, the B cell follicles could also reflect an adaptive immune response against degradation products of the extracellular matrix, becoming so-called neo-self antigens, and may in fact represent an autoimmune process that occurs after breaking the immune tolerance. In order to determine the aetiology of the lymphoid follicles found in $\mathrm{CF}$, future research might focus on lung tissue derived from non-CF bronchiectasis patients who are often colonized with P.aeruginosa, S.aureus and H.influenza as well. If follicles are equally numerous in this disease, their development might have an infectious nature. In COPD, lymphoid follicles were described as aggregates of $\mathrm{B}$ cells that are surrounded by lower numbers of predominantly $\mathrm{CD} 4$ and to lesser extent CD8 T cells $[17,18]$. However, in CF we observed a composition shift of the lymphoid follicles from $\mathrm{B}$ cell to T-cell predominance, suggesting that the cellular adaptive immune response is specifically affected in CF.

We also found that the increased inflammation in end-stage CF lung disease appeared to be genderspecific. Given the lack of apparent differences in patient characteristics between male and female CF patients in our population which may account for the observed female predominance in airway inflammation, there is some room for speculation. It has been shown that oestrogen has a complex immunomodulatory effect on inflammation and mucoid $P$. aeruginosa density [19]. Human CF patients whose lungs are actively infected with $P$. aeruginosa have elevated sputum levels of IL-23 and IL-17 which decrease dramatically following antibiotic treatment $[20,21]$. Experiments with adult male mice demonstrated a critical role for IL-23 (and the Th17 products it induces) in the pathogenesis of murine lung inflammation upon infection with $P$. aeruginosa. Administration of the exogenous female sex hormone $17 \beta$-estradiol (circulating oestrogen) to male CF knockout mice resulted in a more pronounced inflammatory reaction to infection with $P$. aeruginosa, which was reflected by increased lung tissue mRNA levels of IL-23 and IL-17 [22]. Sex hormones also modulate autoimmunity. Autoimmune diseases are a class of illnesses associated with increased Th17 activity and showing distinct gender-based differences in prevalence [19]. The gender-based difference in inflammation in our CF population may be the result of overstimulation of Th17 activity by oestrogens similar to what is seen in autoimmune diseases. Oestrogen can also cause a reduced production of IL-8 in CF bronchial epithelium through inhibition of NF- $\mathrm{kB}$ and IL-8 gene expression. This may result in a hyporesponsive innate immune response in the CF lung during times of high oestrogen exposure and predispose to infection and bacterial colonization [23].

The distinct inflammatory signature in females could have clinical implications. As there is a marked eosinophilic component, a more liberal policy with oral steroids (both during and independent of exacerbations) might be advocated in females. Future clinical trials with anti-inflammatory therapies using monoclonal antibodies may also want to analyse the effect in female CF patients separately.

Although the comprehensive pathological analysis of end-stage CF lung tissue provided a valuable insight in the inflammatory diversity of this disease, our study has some limitations. The origin of our samples only allowed us to study end-stage disease. To visualize disease progression, earlier stages of the disease will need to be studied in a similar way. The study of Regamey et al. who used endobronchial biopsies of children with a median age of 7.3 years to investigate the inflammatory pattern in the bronchial mucosa, already suggested that the infiltrate predominantly consists of macrophages and lymphocytes [24]. Although we did not specifically study the airway compartment when quantifying the lymphoid cells, it is clear that also in our study the CD4 and CD8 $\mathrm{T}$ cells outnumber the $\mathrm{B}$ cells, both as single dispersed cells as in the follicles, where in addition a composition shift to a larger proportion of CD4 T cells in CF compared to controls was noted. However, it seems that the lymphocytic infiltrate in the subepithelial tissue of children with CF has a larger portion of B cells (18\% in CF compared to $13 \%$ in controls) which may indicate that the humoral adaptive response plays a bigger role in the earlier stages of CF lung disease. Moreover, Regamey et al. only found a limited number of neutrophils infiltrating the bronchial mucosa. The numerous presence of 
neutrophils around the airways in our study suggests that they infiltrate the tissue surrounding the airways in later stages of the disease, eventually leading to tissue destruction. A second limitation is that the number of $\mathrm{CF}$ and control tissue included is limited. As a result, we cannot exclude that the observed differences between male and female patients may be partly due to the small sample size. Thirdly, due to the large surface area of the biopsies and the fragile nature of CF lung tissue, we chose to cut nine $\mu \mathrm{m}$ thick sections. This could however confound our results in two ways: it may increase all cell type counts in CF tissue compared with controls, and it may also increase the number of large cell types like macrophages and neutrophils compared with small cells. Therefore, we described our findings in a qualitative way, not elaborating on the extent of the quantitative difference between CF and controls. Moreover, we have not compared cell types to each other but only looked at the differences between groups. A last limitation of our study is the age discrepancy between CF patients and control subjects, due to the fact that transplanted CF patients at our centre are inevitably younger than patients undergoing resection of bronchial carcinoma or in whom lung tissue was obtained after autopsy.

\section{Conclusion}

By quantifying and localizing distinct myeloid and lymphoid subsets in $\mathrm{CF}$ and control lung tissue, the present study clearly showed a diverse inflammatory pattern in end-stage CF lung disease with an increased presence of neutrophils, mast cells, CD1a and CD207 dendritic cells, macrophages, CD8 and CD4 T cells. We also found a large amount of lymphoid follicles showing a composition shift from $\mathrm{B}$ cell to $\mathrm{T}$ cell predominance. Together with the elevated presence of single $\mathrm{T}$ cells and macrophages in CF tissue, this may suggest a role for the cellular adaptive immune system in the pathophysiology of CF. Furthermore, considering the specific increase of eosinophils, mast cells and CD4 T cell counts in the lung tissue of female CF patients, inflammation in the CF lung seemed to be gender-specific in our population. This may be the result of the complex immunomodulatory effects of oestrogen on inflammation.

\section{Additional file}

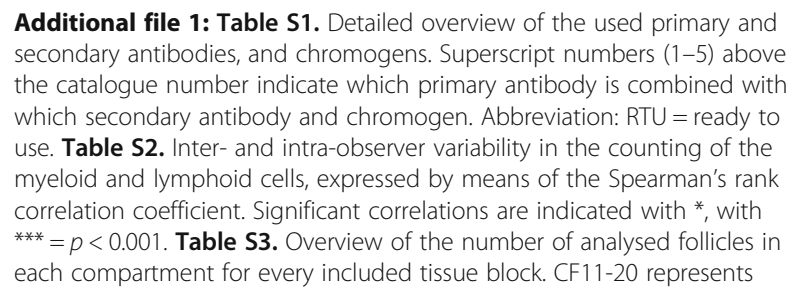

Additional file 1: Table S1. Detailed overview of the used primary and secondary antibodies, and chromogens. Superscript numbers (1-5) above the catalogue number indicate which primary antibody is combined with which secondary antibody and chromogen. Abbreviation: RTU = ready to use. Table S2. Inter- and intra-observer variability in the counting of the myeloid and lymphoid cells, expressed by means of the Spearman's rank correlation coefficient. Significant correlations are indicated with *, with $*^{* *}=p<0.001$. Table S3. Overview of the number of analysed follicles in each compartment for every included tissue block. CF11-20 represents

the female CF patients. Table S4. Quantification of the myeloid cell types and lymphoid follicles according to localization (subdivided in the three compartments: airways, parenchyma and perivascular). The $p$-values in the right-hand column are the result of Kruskal-Wallis 1-way ANOVA testing. Significant differences with airways are indicated with *, with * $=$ $p<0.05,{ }^{* *}=p<0.01$ and ${ }^{* * *}=p<0.001$. These values are the results of Dunn's post hoc testing. Figure S1. Histological section of formalin-fixed paraffin-embedded CF lung tissue. Section was stained for mast cells (tryptase). Representative image showing an airway surrounded by circular fibrosis suggestive of constrictive bronchiolitis. The bronchiole is accompanied by its blood vessel. Abbreviations: AW = airway, BV = blood vessel. Scale bar $=100 \mu \mathrm{m}$. Figure S2. Serial histological sections of formalin-fixed paraffin-embedded CF lung tissue. Both images show the same lymphoid follicles located in the proximity of an airway. Panel A shows a CD20 staining of all B cells lying organised in germinal centres. These are surrounded by a paracortex staining positively for CD3 T cells (panel B). High endothelial venules (green arrowhead) allowing extravasation of naïve B and T cells into the lymphoid follicle are located in the T cell area. AW = airway. Scale bar $=50 \mu \mathrm{m}$. (DOCX $19517 \mathrm{~kb}$ )

\section{Abbreviations}

AB: Antibiotic; CF: Cystic fibrosis; CFTR: Cystic fibrosis transmembrane conductance regulator gene; CRP: C-reactive protein; $\mathrm{FEV}_{1}$ : Forced expiratory volume in 1 s; HPF: High power field; I.V: Intravenous; Ig: Immunoglobulin; IL: Interleukin; LTx: Lung transplantation; NF-KB: Nuclear factor kappa-light-chainenhancer of activated B cells; WBC: White blood cells

\section{Acknowledgements}

The authors would like to thank Herbert Decaluwe, Paul de Leyn, Philippe Nafteux, Dirk Van Raemdonck and Hans Van Veer for providing explanted lung tissue.

\section{Funding}

This research was funded by the Alphonse and Jean Forton Award of the King Baudoin Foundation, a C2 project from the KU Leuven (C24/15/30) and the 7th Framework Programme of the European Union (grant agreement $n^{\circ} 603038$ ).

\section{Availability of data and materials}

The datasets generated during and/or analysed during the current study are available from the corresponding author on reasonable request.

\section{Author's contributions}

EJL prepared the tissue sections, performed the immunohistochemical stainings, quantified the immune cells and drafted the manuscript. EV repeated myeloid cell counts in eight subjects to assess intra-observer variability. $\mathrm{HB}$ helped with tissue sectioning. KVDE and KRB assisted in the immunohistochemical stainings. SEV, GGB and PCG helped with the draft of the manuscript. EKV verified staining reliability and quality. BVM and LJD participated in the design and coordination of the study and helped to draft the manuscript. All authors have read and approved the final manuscript.

\section{Competing interests}

The authors declare that they have no competing interests.

\section{Consent for publication}

Not applicable.

\section{Ethics approval and consent to participate}

The use of lung tissue for scientific research was approved by the hospital's (University Hospitals Leuven) local ethics committee (S52174) and the biobankboard (S51577).

\section{Author details}

${ }^{1}$ Laboratory of Respiratory Diseases, Department of Clinical and Experimental Medicine, University of Leuven, UZ Herestraat 49, Box 7063000 Leuven, Belgium. ${ }^{2}$ Translational Cell and Tissue Research Unit, Department of Imaging and Pathology, University of Leuven, Leuven, Belgium. ${ }^{3}$ Department of Respiratory Medicine, Ghent University Hospital, Ghent, Belgium. ${ }^{4}$ Cystic Fibrosis Unit, Department of Respiratory Diseases, University Hospitals Leuven, Leuven, Belgium. 
Received: 29 April 2016 Accepted: 10 December 2016

Published online: 10 January 2017

\section{References}

1. Davis PB, Drumm M, Konstan MW. Cystic fibrosis. Am J Respir Crit Care Med. 1996;154(5):1229-56.

2. Welsh MJ, Fick RB. Cystic fibrosis. J Clin Invest. 1987;80(6):1523-6.

3. Cohen-Cymberknoh M, Kerem E, Ferkol T, Elizur A. Airway inflammation in cystic fibrosis: molecular mechanisms and clinical implications. Thorax. 2013;68(12):1157-62.

4. Stoltz DA, Meyerholz DK, Welsh MJ. Origins of cystic fibrosis lung disease. N Engl J Med. 2015;372(16):1574-5.

5. Watt AP, Courtney J, Moore J, Ennis M, Elborn JS. Neutrophil cell death, activation and bacterial infection in cystic fibrosis. Thorax. 2005;60(8):659-64.

6. Braun AT, Merlo CA. Cystic fibrosis lung transplantation. Curr Opin Pulm Med. 2011;17(6):467-72.

7. Yonker LM, Cigana C, Hurley BP, Bragonzi A. Host-pathogen interplay in the respiratory environment of cystic fibrosis. J Cyst Fibros. 2015;14(4):431-9.

8. Hartl D, Gaggar A, Bruscia E, Hector A, Marcos V, Jung A, et al. Innate immunity in cystic fibrosis lung disease. J Cyst Fibros. 2012;11(5):363-82.

9. Andersson CK, Andersson-Sjoland A, Mori M, Hallgren O, Pardo A, Eriksson L, et al. Activated MCTC mast cells infiltrate diseased lung areas in cystic fibrosis and idiopathic pulmonary fibrosis. Respir Res. 2011;12:139.

10. Azzawi M, Johnston PW, Majumdar S, Kay AB, Jeffery PK. T lymphocytes and activated eosinophils in airway mucosa in fatal asthma and cystic fibrosis. Am Rev Respir Dis. 1992;145(6):1477-82.

11. Hausler M, Schweizer K, Biesterfel S, Opladen T, Heimann G. Peripheral decrease and pulmonary homing of CD4 + CD45RO+ helper memory $T$ cells in cystic fibrosis. Respir Med. 2002;96(2):87-94.

12. Hubeau C, Lorenzato M, Couetil JP, Hubert D, Dusser D, Puchelle E, et al. Quantitative analysis of inflammatory cells infiltrating the cystic fibrosis airway mucosa. Clin Exp Immunol. 2001;124(1):69-76.

13. Kerem E, Reisman J, Corey M, Canny GJ, Levison H. Prediction of mortality in patients with cystic fibrosis. N Engl J Med. 1992;326(18):1187-91.

14. Rosenfeld M, Davis R, FitzSimmons S, Pepe M, Ramsey B. Gender gap in cystic fibrosis mortality. Am J Epidemiol. 1997;145(9):794-803.

15. Harness-Brumley CL, Elliott AC, Rosenbluth DB, Raghavan D, Jain R. Gender differences in outcomes of patients with cystic fibrosis. J Womens Health (La). 2014;23(12):1012-20.

16. Olesen HV, Pressler T, Hjelte L, Mared L, Lindblad A, Knudsen PK, et al. Gender differences in the Scandinavian cystic fibrosis population. Pediatr Pulmonol. 2010;45(10):959-65.

17. Brusselle GG, Demoor T, Bracke KR, Brandsma CA, Timens W. Lymphoid follicles in (very) severe COPD: beneficial or harmful? Eur Respir J. 2009;34(1):219-30.

18. Yadava K, Marsland BJ. Lymphoid follicles in chronic lung diseases. Thorax. 2013;68(6):597-8.

19. Sweezey NB, Ratjen F. The cystic fibrosis gender gap: potential roles of estrogen. Pediatr Pulmonol. 2014;49(4):309-17.

20. Decraene A, Willems-Widyastuti A, Kasran A, De BK, Bullens DM, Dupont LJ. Elevated expression of both mRNA and protein levels of IL-17A in sputum of stable Cystic Fibrosis patients. Respir Res. 2010;11:177.

21. McAllister F, Henry A, Kreindler JL, Dubin PJ, Ulrich L, Steele C, et al. Role of IL-17A, IL-17F, and the IL-17 receptor in regulating growth-related oncogene-alpha and granulocyte colony-stimulating factor in bronchial epithelium: implications for airway inflammation in cystic fibrosis. J Immunol. 2005;175(1):404-12.

22. Wang Y, Cela E, Gagnon S, Sweezey NB. Estrogen aggravates inflammation in Pseudomonas aeruginosa pneumonia in cystic fibrosis mice. Respir Res. 2010;11:166.

23. Chotirmall SH, Greene CM, Oglesby IK, Thomas W, O'Neill SJ, Harvey BJ, et al. 17Beta-estradiol inhibits IL-8 in cystic fibrosis by up-regulating secretory leucoprotease inhibitor. Am J Respir Crit Care Med. 2010;182(1):62-72.

24. Regamey N, Tsartsali L, Hilliard TN, Fuchs O, Tan HL, Zhu J, et al. Distinct patterns of inflammation in the airway lumen and bronchial mucosa of children with cystic fibrosis. Thorax. 2012;67(2):164-70.

\section{Submit your next manuscript to BioMed Central and we will help you at every step:}

- We accept pre-submission inquiries

- Our selector tool helps you to find the most relevant journal

- We provide round the clock customer support

- Convenient online submission

- Thorough peer review

- Inclusion in PubMed and all major indexing services

- Maximum visibility for your research

Submit your manuscript at www.biomedcentral.com/submit
Biomed Central 